\title{
Thermodynamic Analysis of a Power Plant Waste Heat Driven Absorption Refrigeration System
}

\author{
Mohamad Mehyo, Hakan Ozcan, Ahmed Hassan Ahmed Hassan \\ Department of Mechanical Engineering, Ondokuz Mayis University \\ Körfez Mahallesi, 19 Mayıs Ünv. Kurupelit Kampüsü, 55105 Atakum, Samsun, Turkey \\ 15210438@stu.omu.edu.tr; ozcanh@omu.edu.tr; 15210457@stu.omu.edu.tr
}

\begin{abstract}
Assessment of the exergetical and energical performance of a single-stage $\mathrm{NH}_{3}-\mathrm{NaSCN}$ absorption refrigeration system has carried out for the effective recovery of low-temperature waste heat of the drainage tanks in AL-Zara thermal power plant in Hama, Syria. Thermodynamic analysis, both first and second law, has employed to be a tool for consideration of the quantity and quality of energy in the thermal system. Exergy analysis has determined the destruction and losses of exergy in various components and hence in the overall system. The thermal properties, entropy, and exergy of the working mixture have also calculated to analyze irreversible loss in system components under operating conditions by MATLAB ${ }^{\circledR}$ computer program. The obtained numerical results for the cycle have tabulated where the coefficient of performance and the coefficient of performance for heating have reached up to $0.55,1.55$ respectively. The efficiencies of the second law of thermodynamics for cooling and heating applications have reached up to $0.295,1.295$ respectively.
\end{abstract}

Keywords: Power Plant, Waste heat, Absorption Refrigeration, NH3-NaSCN, Exergy.

\section{Introduction}

Refrigeration systems are generally driven by electrical power and use mechanical vapor compression circulates. Absorption chillers are an alternative approach; whose use the thermal power (industrial waste heat, renewable energy sources, or other thermal sources) as a driving force. Furthermore, absorption cooling systems do not cause ozone depletion, as long they use natural substances, as working fluids [9].

A lot of researchers have studied various absorption refrigeration systems which use different thermal energy sources. Kaushik et al. [10] have studied an absorption refrigeration cycle with a required temperature of the heat source varies from 60 to $200{ }^{\circ} \mathrm{C}$, depending on its configuration. The required source temperature for single effect cycle is $80-100{ }^{\circ} \mathrm{C}$. Arora et al. $[11,12]$ have developed a double effect cycle $120-150^{\circ} \mathrm{C}$, half effect $60-75^{\circ} \mathrm{C}$ and triple effect cycles which require generator temperature even higher than $150{ }^{\circ} \mathrm{C}$. Many ideas were used solar and waste thermal energy to operate a doublestage absorption refrigeration system [13-16]. It is observed from these works that double-stage plants have higher COP than single-stage plants but their specific costs and the required driving temperatures are also higher. Vidala et al. [17] have developed a new combined cycle by performing an exergy analysis method. This cycle by using ammonia-water mixture produced both power and cooling simultaneously from one heat source. Khaliq et al. [18] have studied a tri-generation system depending on a gas turbine cycle and recovering the heat for a steam generator and an absorption cooling cycle. First and second law concepts were used with computational analysis to study effects of overall parameters of the cycle (pressure ratio, turbine inlet temperature, the pressure drop in combustor and heat recovery steam generator, and evaporation temperature) on the exergy in every component. Jonsson and Yan et al. [19] have found that using high temperature of the waste heat enhances the efficiency of the cycles.

A number of researchers have conducted energy and exergy analysis for refrigeration systems. However, there is a few academic work on exergy analysis for the NH3-NaSCN system found in open literature. Thus the aim of this study is to obtain the exergetic and energical analysis of a single-stage absorption refrigeration system, which uses Ammonia-Sodium Thiocyanate (NH3-NaSCN) as a working solution, driven by the waste heat source of drainage tanks of the three generating sets of AL-Zara thermal power plant. Thermodynamic analysis, both first and second law, is employed to be a tool for consideration of the quantity and quality of energy in the thermal system. Exergy analysis is determined the destruction and losses of exergy in various components and hence in the overall system. The thermal properties, entropy, and exergy of the 
working mixture are also calculated to analyze irreversible loss in system components under operating conditions by MATLAB ${ }^{\circledR}$ computer program.

\section{System Description}

This system is three cooling units, each of them consists of an absorption system which is operated by the drainage tank water energy, by using NH3-NaSCN as a working solution [1]. Fig. 1 shows the scheme of a single-stage absorption refrigeration system:

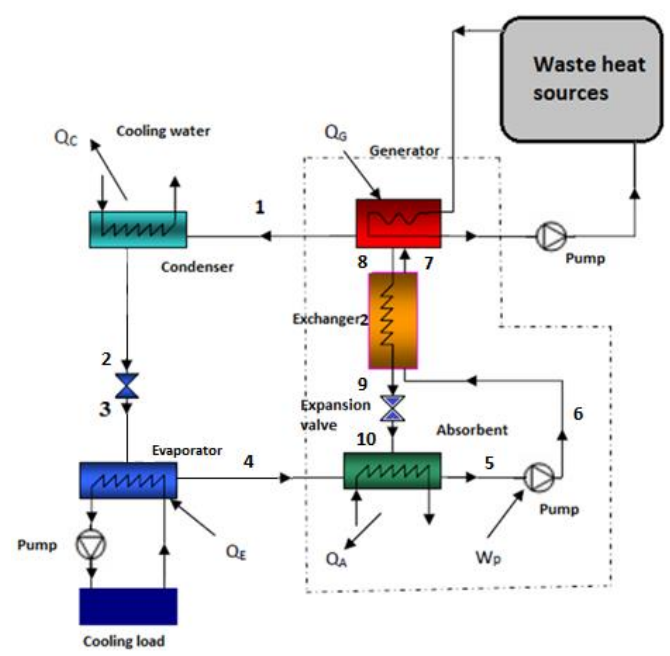

Fig. 1: Schema of a simple system of an absorption cooling cycle works by waste heat.

The most important components of the single-stage absorption cycle are condenser, evapourator, absorber, pumps, heat exchanger (opposite heat exchanger) and the generator. The high pressure in the cycle is the condenser pressure that is equal to the generator pressure while the evapourator pressure is the low pressure which is equal to the absorber pressure. The pump raises the pressure of the solution from the low pressure to the high pressure. The solution is heated in the generator by waste heat (or any other thermal source) in order to make the refrigerant starts separating from the solution, and going to the condenser where it condenses. Then the refrigerant pressure is reduced by the expansion valve before it enters the evapourator. It is obtained the cooling load in the evapourator as a result of evapouration of the refrigerant at a low pressure. In the absorber, the vapour of refrigerant is absorbed which comes from the evapourator by the refrigeration solution which returns from the generator (after reducing the pressure by the expansion valve), and it is produced a heat as a result of the absorption process, which requires cooling the absorber[2]. The value of the pump work is so small compared with the amount of heat which is added to the generator, where it can be neglected because the work which is required to lift the fluid pressure far less than the work which is necessary to compress the vapour between the same values of pressure.

\section{Thermodynamic Analysis}

In order to perform the thermodynamic analysis, the assumptions made are [20]:

1. The cycle is under steady-state operation.

2. Pressure drop in pipes and pump's work are negligible values.

3. The states at the exit of condenser and evaporator are saturated liquid and saturated vapour respectively.

4. Kinetic, chemical and potential exergies are neglected and only physical exergy is considered.

5. In order to avoid crystallization, temperature of strong solution exiting the solution heat exchanger is kept $7-8{ }^{\circ} \mathrm{C}$ above crystallization temperature.

6. $\mathrm{NH}_{3}$ in the absorber and generator are in an equilibrium state at their respective pressure and temperature.

7. The $\mathrm{NH}_{3}$ at the exit of the generator and absorber is saturated.

8. Heat loss to the surrounding is neglected.

For the thermodynamic analysis, the required parameters are given in Table 1. 
Table 1: Parameters which used in the modelling [8].

\begin{tabular}{|l|l|}
\hline Parameters & Value \\
\hline Environment temperature $\left({ }^{\circ} \mathrm{C}\right)$ & 25 \\
\hline Environment pressure $(\mathrm{kPa})$ & 101.35 \\
\hline Mass flow rate of waste tanks water $(\mathrm{kg} / \mathrm{s})$ & 2.83 \\
\hline Drainage tanks efficiency $(\%)$ & $\approx 100$ \\
\hline Generator temperature $\left({ }^{\circ} \mathrm{C}\right)$ & 90 \\
\hline Evaporator temperature $\left({ }^{\circ} \mathrm{C}\right)$ & -5 \\
\hline Condenser and Absorber temperature $\left({ }^{\circ} \mathrm{C}\right)$ & 30 \\
\hline
\end{tabular}

For the systems which use the $\mathrm{NH}_{3}-\mathrm{NaSCN}$ solution as a working solution, the thermodynamic properties are very important. For the enthalpy and the entropy values of this solution, many equations have been developed in the literature. For $\mathrm{NH}_{3}-\mathrm{NaSCN}$ mixture, in this study, the thermodynamic properties have been studied by Infante Ferreira [21]. Where the $\mathrm{NH}_{3}$ is the refrigerant and $\mathrm{NaSCN}$ is absorbent. The relation between saturation pressure, concentration and temperature are expressed as:

$$
\ln p=A+\frac{B}{T}
$$

Where: $A=15.7266-0.298628 X$, and $B=-2548.62-2621.92(1-X)^{3}$.

The relation between temperature, concentration and enthalpy is expressed as:

$$
h=A+B(T-273.15)+C(T-273.15)^{2}+D(T-273.15)^{3}
$$

Where: $A=79.72-1072 X+1287.9 X^{2}-295.67 X^{3}, \quad B=2.4081-2.2814 X+7.9291 X^{2}-3.5137 X^{3}, C=10^{-2}\left(1.255 X-4 X^{2}+3.06 X^{3}\right)$ and $D=10^{-5}\left(-3.33 X+10 X^{2}-3.33 X^{3}\right)$.

The two stage equilibrium pressure and temperature of the refrigerant $\mathrm{NH}_{3}$ are obtained by the following relation:

$$
P=10^{3} \sum_{i=0}^{6} a_{i}(T-273.15)^{i}
$$

For saturated liquid and vapour of $\mathrm{NH}_{3}$, the specific enthalpies are obtained as follows:

$$
h_{l}=\sum_{i=0}^{6} b_{i}(T-273.15)^{i}, \quad h_{V}=\sum_{i=0}^{6} c_{i}(T-273.15)^{i}
$$

The above two equations are fitted by Sun [22] with source data taken from ASHRAE handbook [7]. The coefficients are listed in Table 2.

The relation between temperature and specific enthalpies of superheated vapour $\mathrm{NH}_{3}$ is given as:

$$
h_{\text {sup erheated }}\left(T_{2}\right)=h_{\text {sturated }}\left(T_{1}\right)+\int_{T_{1}}^{T_{2}} c_{p} d T
$$


Where: $T_{1}$ is the saturated temperature corresponding to the pressure of this superheated vapor $\mathrm{NH}_{3}$ and $h_{\text {sturated }}\left(T_{1}\right)$ is the corresponding enthalpy, $T_{2}$ is the temperature of the superheated vapor $\mathrm{NH}_{3}, h_{\text {superheated }}\left(T_{2}\right)$ is the corresponding enthalpy. $c_{P}$ is the specific heat and is obtained as:

$$
c_{p}=\sum_{i=0}^{6} d_{i}(T-273.15)^{i}
$$

The above two equation are obtained by Zhu [23] with source data are taken from the properties of R-717 (ANHYDROUS AMMONIA) [3], and the coefficient di is listed in Table 2.

Table 2: coefficients of equations 3,4 and 6 .

\begin{tabular}{|c|c|c|c|c|}
\hline$i$ & $a_{i}$ & $b_{i}$ & $c_{i}$ & $\mathrm{~d}_{\mathrm{i}}$ \\
\hline 0 & $4.2871 * 10^{-1}$ & $1.9879 * 10^{2}$ & $1.4633^{*} 10^{3}$ & $1.7467 * 10^{4}$ \\
\hline 1 & $1.6001 * 10^{-2}$ & $4.4644 * 10^{0}$ & $1.2839 * 10^{0}$ & $-3.3129 * 10^{2}$ \\
\hline 2 & $2.3652 * 10^{-4}$ & $6.2790^{*} 10^{-3}$ & $-1.1501 * 10^{-2}$ & $2.6189^{*} 10^{0}$ \\
\hline 3 & $1.6132 * 10^{-6}$ & $1.4591 * 10^{-4}$ & $-2.1523^{*} 10^{-4}$ & $-1.1045^{*} 10^{-2}$ \\
\hline 4 & $2.4303 * 10^{-9}$ & $-1.5262 * 10^{-6}$ & $1.9055^{*} 10^{-6}$ & $2.6214 * 10^{-5}$ \\
\hline 5 & $-1.2494 * 10^{-11}$ & $-1.8069 * 10^{-8}$ & $2.5608 * 10^{-6}$ & $-3.3202^{*} 10^{-8}$ \\
\hline 6 & $1.9054^{-13} 10^{-13}$ & $1.9054 * 10^{-10}$ & $-2.5964 * 10^{-10}$ & $1.7539 * 10^{-11}$ \\
\hline
\end{tabular}

Because of the entropy of $\mathrm{NH}_{3}-\mathrm{NaSCN}$ solutions has not been investigated before the used entropy data in this study are the entropy of $\mathrm{LiBr}-\mathrm{H}_{2} \mathrm{O}$ solutions which are taken from the Linghui Zhu, Junjie Gu study [24]. In order to simplify the entropy equations, the pressure dependence of the entropy can be considered negligible, consequently, the entropy is a function of the mixture concentration and the related temperature only. depending on this assumption, at constant concentrations, the entropy of $\mathrm{NH}_{3}-\mathrm{NaSCN}$ at $25^{\circ} \mathrm{C}$ is expressed as following:

$$
S_{25}=\frac{h_{\text {sol }}-g_{\text {sol }}}{298.15}
$$

Where Gibbs' free energy of mixture can be expressed as partial molar quantities [25]:

$$
g_{\text {Sol }}=\frac{X}{M_{N_{3}}} \mu_{N_{3}}+\frac{1-X}{M_{N a S C N}} \mu_{N a S C N}
$$

Where $X$ is the solution concentration, $M$ is the molecular weight $\left(M_{N a S C N}=81.072 \mathrm{~g} / \mathrm{mol}, M_{N H 3}=17.031 \mathrm{~g} / \mathrm{mol}\right)$ and the chemical potential of $\mathrm{NH}_{3}$ and $\mathrm{NaSCN}$ are:

$$
\begin{gathered}
\mu_{\mathrm{NH}_{3}}=\left(\bar{h}_{v}-298.15 \cdot \bar{S}_{v}\right)_{\mathrm{NH}_{3}} \\
\mu_{\mathrm{NaSCN}}=596.3 R \cdot \ln \left(m_{\mathrm{NaSCN}} \cdot \gamma\right)+298.15 \bar{K}+\mu^{*}{ }_{\mathrm{NaSCN}}
\end{gathered}
$$

Where: $\bar{K}=0.1922 \mathrm{KJ} / \mathrm{kmol} . \mathrm{K}, m_{\mathrm{NaSCN}}$ the NaSCN molality and the mean ionic activity coefficient $y$ are now obtained as following. For a single electrolyte solution at $25^{\circ} \mathrm{C}$ [4].

$$
m_{N a S C N}=\frac{X}{81.072(1-X)}
$$


The chemical potential of pure $\mathrm{NaSCN}$ is:

$$
\mu_{\text {NaSCN }}^{*}=\left(\bar{h}-T_{r e f} \cdot \bar{S}\right)_{N a S C N}
$$

This potential becomes zero as pure $\mathrm{NaSCN}$ at $25^{\circ} \mathrm{C}$ has been assigned a zero enthalpy and entropy.

$$
\Gamma^{0}=\left[1+B\left(1+\frac{I}{10}\right)^{q}-B\right] \cdot \Gamma^{*}
$$

Where $\mathbb{\Gamma}^{0}$ is the reduced activity coefficient of pure solution at $25^{\circ} C, B=0.75-0.065 q: q$ is Meissner's parameter $(q=7.27)$.

$$
\begin{aligned}
& \ln \Gamma^{*}=(-0.5107 \sqrt{I}) /(1+C \sqrt{I}) \\
& C=1+0.055 q \exp \left(-(0.023 I)^{3}\right)
\end{aligned}
$$

Where $I$ is the ionic strength ( $I=\frac{1}{2} \sum m_{i} Z_{i}^{2}=m_{N a S C N}$ ), $Z$ is the number of charges on the cation or anion. Then the mean molar ionic activity coefficient is calculated from the following relation:

$$
\gamma=\left(\Gamma^{0}\right)^{Z_{+} Z_{-}}=\Gamma^{0}
$$

The entropy of mixture at $T$ temperature is expressed as:

$$
S_{t}=S_{25}-\frac{R}{M_{s o l}}\left[\bar{X}_{N a S C N} \ln \left(\bar{X}_{N a S C N} \cdot \gamma\right)+\bar{X}_{N H_{3}} \ln \left(p / p^{*}\right)\right]
$$

Where: $R=8.314 \mathrm{~kJ} / \mathrm{kmol} . K, M_{\text {sol }}$ is the Solution Molecular Weight, which is $M_{\text {sol }}$ expressed as:

$$
M_{\text {sol }}=\frac{17.031}{1-0.7962 X}
$$

$\overline{\mathrm{X}}=$ mole fractions of $\mathrm{NaSCN}$ and $\mathrm{NH}_{3}$; for $\mathrm{NH}_{3}$ it is given as follows:

$$
\bar{X}_{N_{3}}=\frac{81.072 X}{81.072 X+17.031(1-X)}
$$

$P$ and $P^{*}=$ pressure of $\mathrm{NH}_{3}$ vapor of the solution and pure $\mathrm{NH}_{3}$.

The energy and exergy analysis of the refrigeration system include the use of first and second law of thermodynamics. The relations which used in the calculation of the cycle are given in Table 3 for every component and for overall cycle. 
Table 3: Mass, energy, and exergy equations for each component and for the overall cycle $[5,6]$.

\begin{tabular}{|c|c|c|c|}
\hline Component & Mass equation & Energy relations & Exergy relations \\
\hline Generator & $\dot{m}_{7}-\dot{m}_{1}-\dot{m}_{8}=0$ & $\dot{Q}_{G}+\dot{m}_{7} h_{7}-\dot{m}_{1} h_{1}-\dot{m}_{8} h_{8}=0$ & $\begin{array}{l}\dot{E}_{1}=\dot{m}_{1}\left(h_{1}-h_{0}-T_{0}\left(s_{1}-s_{0}\right)\right) \\
\dot{E}_{7}=\dot{m}_{7}\left(h_{7}-h_{0}-T_{0}\left(s_{7}-s_{0}\right)\right) \\
\dot{E}_{8}=\dot{m}_{8}\left(h_{8}-h_{0}-T_{0}\left(s_{8}-s_{0}\right)\right)\end{array}$ \\
\hline Condenser & $\dot{m}_{1}-\dot{m}_{2}=0$ & $\dot{m}_{1} h_{1}-\dot{Q}_{C}-\dot{m}_{2} h_{2}=0$ & $\dot{E}_{2}=\dot{m}_{2}\left(h_{2}-h_{0}-T_{0}\left(s_{2}-s_{0}\right)\right)$ \\
\hline $\begin{array}{c}\text { Expansion } \\
\text { valve } 1\end{array}$ & $\dot{m}_{2}-\dot{m}_{3}=0$ & $\dot{m}_{2} h_{2}-\dot{m}_{3} h_{3}=0, h_{2}-h_{3}=0$ & $\dot{E}_{3}=\dot{m}_{3}\left(h_{3}-h_{0}-T_{0}\left(s_{3}-s_{0}\right)\right)$ \\
\hline Evaporator & $\dot{m}_{3}-\dot{m}_{4}=0$ & $\dot{Q}_{E}+\dot{m}_{3} h_{3}-\dot{m}_{4} h_{4}=0$ & $\dot{E}_{4}=\dot{m}_{4}\left(h_{4}-h_{0}-T_{0}\left(s_{4}-s_{0}\right)\right)$ \\
\hline Absorber & $\dot{m}_{4}+\dot{m}_{10}-\dot{m}_{5}=0$ & $\dot{m}_{4} h_{4}+\dot{m}_{10} h_{10}-\dot{Q}_{A}-\dot{m}_{5} h_{5}=0$ & $\begin{array}{c}\dot{E}_{5}=\dot{m}_{5}\left(h_{5}-h_{0}-T_{0}\left(s_{5}-s_{0}\right)\right) \\
\dot{E}_{10}=\dot{m}_{10}\left(h_{10}-h_{0}-T_{0}\left(s_{10}-s_{0}\right)\right)\end{array}$ \\
\hline $\begin{array}{l}\text { Expansion } \\
\text { valve } 2 \\
\end{array}$ & $\dot{m}_{9}-\dot{m}_{10}=0$ & $\dot{m}_{9} h_{9}-\dot{m}_{10} h_{10}=0, h_{9}-h_{10}=0$ & $\dot{E}_{9}=\dot{m}_{9}\left(h_{9}-h_{0}-T_{0}\left(s_{9}-s_{0}\right)\right)$ \\
\hline $\begin{array}{c}\text { Heat } \\
\text { exchanger }\end{array}$ & $\begin{array}{l}\dot{m}_{6}-\dot{m}_{7}=0 \\
\dot{m}_{9}-\dot{m}_{8}=0\end{array}$ & $\dot{m}_{6} h_{6}-\dot{m}_{7} h_{7}+\dot{m}_{8} h_{8}-\dot{m}_{9} h_{9}=0$ & $\dot{E}_{6}=\dot{m}_{6}\left(h_{6}-h_{0}-T_{0}\left(s_{6}-s_{0}\right)\right)$ \\
\hline Pump & $\dot{m}_{5}-\dot{m}_{6}=0$ & $W_{P}=\dot{m}_{5}\left(h_{5}-h_{6}\right)$ & \\
\hline $\begin{array}{l}\text { Overall } \\
\text { cycle }\end{array}$ & $\begin{array}{r}\dot{m}_{\text {solution }}= \\
f=\frac{\left.\dot{m}_{7}\right)}{\dot{m}_{1}}(K \\
C O P=\frac{\dot{Q}_{E}}{\dot{Q}_{G}}(\mathrm{Co} \\
\varepsilon_{\text {ed }}=1+C O P(\mathrm{C} \\
\dot{Q}_{G}+\end{array}$ & $\begin{array}{l}\text { dium thiocyanze }+\dot{m}_{\text {ammonia }} \\
=\dot{m}_{1} X_{1}+\dot{m}_{8} X_{8} \\
K_{\text {ref }} \text { ) (circulation ratio) } \\
\text { icient of Performance of cooling) } \\
+W_{P}=\dot{Q}_{A}+\dot{Q}_{C}\end{array}$ & $\begin{array}{c}\eta_{\text {exergy }}=\dot{E}_{E} / \dot{E}_{G} \\
\dot{E}_{E}=\dot{E}_{4}-\dot{E}_{3}, \quad \dot{E}_{G}=\dot{E}_{1}+\dot{E}_{8}-\dot{E}_{7} \\
\dot{E}_{D, E}=\dot{E}_{3}-\dot{E}_{4}+\dot{Q}_{E}\left(1-T_{0} / T_{E}\right) \\
\dot{E}_{D, G}=\dot{E}_{7}-\dot{E}_{8}-\dot{E}_{1}+\dot{Q}_{G}\left(1-T_{0} / T_{G}\right) \\
\dot{E}_{D, A}=\dot{E}_{4}+\dot{E}_{10}-\dot{E}_{5}-\dot{Q}_{A}\left(1-T_{0} / T_{A}\right) \\
\dot{E}_{D, C}=\dot{E}_{1}-\dot{E}_{2}-\dot{Q}_{C}\left(1-T_{0} / T_{C}\right) \\
\dot{E}_{D, H E}=\dot{E}_{6}+\dot{E}_{8}-\dot{E}_{7}-\dot{E}_{9} \\
\dot{E}_{D, O C}=\dot{E}_{D, G}+\dot{E}_{D, E}+\dot{E}_{D, A}+\dot{E}_{D, C} \\
+\dot{E}_{D, H E_{1}}+\dot{E}_{D, H E_{2}}\end{array}$ \\
\hline
\end{tabular}

Where $\dot{m}$ is the mass flow rate, $\dot{E}$ the exergy of the fluid at temperature $T$. The terms $h$ and $s$ are the enthalpy and entropy of the fluid respectively, $h_{o}$ and $s_{o}$ are the enthalpy and entropy of the fluid at environmental temperature $T_{0}$. In this study, $T_{0}$ was taken as $298.15 \mathrm{~K}$.

The NH3- NaSCN absorption heat transformer cycle is analyzed and compared thermodynamically. The computer program is written based on heat and mass balances, heat transfer equations, the mathematical equations model and thermodynamic properties equations of solution and refrigerant. Here the computer codes are designed to analyze both first law and second law analysis. 


\section{Results and Discussion}

The values of temperature, enthalpy, entropy, mass flow rate, concentration exergy of the fluid at all points of the absorption cycle are obtained by using MATLAB ${ }^{\circledR}$ program depending on the available parameters. The results are presented in Table 4. The results of the first law analysis of current system are presented in Table 5. For MATLAB®, the input parameters are taken as $T_{G}=90^{\circ} \mathrm{C}, T_{C}=T_{A}=25^{\circ} \mathrm{C}, T_{E}=-10^{\circ} \mathrm{C}$, $\eta_{H E}=0.8$.

Table 4: Results of thermodynamic analysis of the absorption refrigeration cycle.

\begin{tabular}{|c|c|c|c|c|c|c|c|}
\hline Steps & $T\left({ }^{\circ} \mathrm{C}\right)$ & $h(\mathrm{~kJ} / \mathrm{kg})$ & $s(\mathrm{~kJ} / \mathrm{kg} \mathrm{K})$ & $\dot{m}(\mathrm{~kg} / \mathrm{s})$ & $X\left(\mathrm{NH}_{3}\right)$ & $\dot{E}(\mathrm{~kW})$ & $P(\mathrm{kPa})$ \\
\hline 1 & 90 & 1690 & 4.337 & 0.01371 & 1 & 5.648 & 1002.3 \\
\hline 2 & 25 & 315.55 & 1.123 & 0.01371 & 1 & 0 & 1002.3 \\
\hline 3 & 25 & 315.55 & 1.123 & 0.01371 & 1 & 0 & 291.56 \\
\hline 4 & -10 & 1450.5 & 5.473 & 0.01371 & 1 & -2.289 & 291.56 \\
\hline 5 & 25 & -102.9 & 0.726 & 0.10756 & 0.4618 & 0 & 291.56 \\
\hline 6 & 25 & -102.9 & 0.726 & 0.10756 & 0.4618 & 0 & 1002.3 \\
\hline 7 & 68 & 15.650 & 1.033 & 0.10756 & 0.4618 & 2.805 & 1002.3 \\
\hline 8 & 90 & 71.832 & 1.056 & 0.09470 & 0.3843 & 4.931 & 1002.3 \\
\hline 9 & 38 & -62.813 & 0.747 & 0.09470 & 0.3843 & 0.911 & 1002.3 \\
\hline 10 & 38 & -62.813 & 0.747 & 0.09470 & 0.3843 & 0.911 & 291.56 \\
\hline
\end{tabular}

Table 5: Heat transfer rates and performances of the cycle.

\begin{tabular}{|l|l|}
\hline Component & Heat transfer rates $(\mathrm{kW})$ \\
\hline Generator & 28.300 \\
\hline Condenser & 18.846 \\
\hline Evaporator & 15.565 \\
\hline Absorber & 25.006 \\
\hline \multicolumn{2}{|c|}{ Performance parameters } \\
\hline Coefficient of performance for cooling $(\mathrm{COP})$ & 0.55 \\
\hline Coefficient of performance for heating $\left(\varepsilon_{e d}\right)$ & 1.55 \\
\hline Circulation ratio $(f)$ & 7.845 \\
\hline
\end{tabular}

The results of the second law analysis are listed in Table 6. It can observed clearly that the highest exergy loss has occurred in the condenser, and then the generator, the absorber, and the evaporator.

Table 6: Exergy loss rates and exergetic efficiencies of the cycle.

\begin{tabular}{|l|l|l|}
\hline Component & Exergy loss rate $(\mathrm{kW})$ & Non-dimensional exergy loss (\%) \\
\hline Generator & 2.708 & 23.17 \\
\hline Condenser & 5.648 & 48.34 \\
\hline Evaporator & 0.218 & 1.865 \\
\hline Absorber & 1.894 & 16.21 \\
\hline Heat exchanger & 1.215 & 10.39 \\
\hline Total & 11.683 & 100 \\
\hline Exergetic efficiency for cooling $\left(\eta_{\text {exergy,co }}\right)$ & 0.2942 & \\
\hline Exergetic efficiency for heating $\left(\eta_{\text {exergy,he }}\right)$ & 1.2942 & \\
\hline
\end{tabular}




\section{Conclusion}

In this study, the first and the second law of thermodynamics are performed to a single stage $\mathrm{NH}_{3}-\mathrm{NaSCN}$ absorption system for cooling and heating applications, the performance analysis and exergy of each component are studied. The results show that the cooling system and heating at this study conditions are $C O P=0.55, \varepsilon_{e d}=1.55$ respectively. The efficiencies of the second law of thermodynamics for cooling and heating applications are $\eta_{\text {exergy, co }}=0.2942$, $\eta_{\text {exergy, he }}=1.2942$ respectively.

Finally, the results of the energy and exergy analysis presented in this paper for the single-stage absorption refrigeration system which is carried out for the effective recovery of low-temperature waste heat of the drainage tanks in AL-Zara steam power plant can be applied as a useful tool for evaluation and improvement of this absorption system, it provides a simple and effective method to identify how losses at different devices are interdependent.

\section{References}

[1] R. Al-Masri, S. Ajib, W. Naameh, M. A. Sayegh, R. George and T. Kassem. Reference in the principles of solar thermal applications. Al-Baath University publications, 2008.

[2] M. M. El-Sayed, A. K. Fathy and S. A. Mogahed. Computational Models of Solar Thermal Systems. Center for Scientific Publishing King Abdulaziz University, Jeddah, 808.1998.

[3] Properties of R-717 (anhydrous ammonia), handbook, Industrial refrigeration consortium. University of Wisconsin, Madison, WI, USA.

[4] J. F. Zemaitis, D. M. Clark, M. Rafal and N. C. Scrivner. Handbook of aqueous electrolyte thermodynamics. New York: American Institute of Chemical Engineers, 1986.

[5] K. Annamalai and I. K. Puri. Advanced thermodynamics engineering, CRC Press LLC, 2002.

[6] I. Dincer and M. A. Rosen, Exergy, energy, Environment And Sustainable Development, 1st ed. Elsevier Ltd, 2007.

[7] ASHRAE, Handbook, fundamentals, Chapter 17. ASHRAE: Atlanta, GA, 17.45, 17.81, 1993.

[8] The archive of the AL-ZARA, Thermal Power Plant, 2010.

[9] O. Kaynakli and M. Kilic, "Theoretical study on the effect of operating conditions on performance of absorption refrigeration system," Energy conversion and management, vol. 48, no. 2, pp. 599-607, 2007.

[10] S. C. Kaushik and A. Arora, "Energy and exergy analysis of single effect and series flow double effect water-lithium bromide absorption refrigeration systems," International Journal of Refrigeration, vol. 32, no. 6, pp. 1247-1258, 2009.

[11] A. Arora, M. Dixit and S. C. Kaushik. "Energy and exergy analysis of a double effect parallel flow $\mathrm{LiBr} / \mathrm{H} 2 \mathrm{O}$ absorption refrigeration system," Journal of Thermal Engineering, vol. 2, no. 1, pp. 541-549, 2016 .

[12] A. Arora, M. Dixit and S. C. Kaushik, "Computation of optimum parameters of a half effect water lithium bromide vapour absorption refrigeration system," Journal of Thermal Engineering, vol. 2, no. 2, pp. 683-692, 2016b.

[13] N. E. Wijeysundera, "An irreversible-thermodynamic model for solar-powered absorption cooling systems," Sol Energy, vol. 68, no. 1, pp. 69-75, 2000.

[14] S. Alizadeh, "Multi-pressure absorption cycles in solar refrigeration: a technical and economical study," Sol Energy, vol. 69 , no. 1 , pp. 37-44, 2000.

[15] A. Lokurlu and F. Richarts, "Zweistufige Absorptionskältemaschine mit Parabolrinnenkollektoren," Band Zweites Symposium Solares Kühlen in der Praxis, HfT Stuttgart, 2002, pp. 98-109.

[16] C. Schweigler, "Solare Klimatisierung mit zweistufigem Absorptionskälteanlage," Band Drittes Symposium Solares Kuhlen in der Praxis, HfT Stuttgart, 2004, pp. 211-229.

[17] A. Vidala, R. Best, R. Rivero and J. Cervantes, "Analysis of a combined power and refrigeration cycle by the exergy method," Energy, vol. 31, pp. 3401-3414, 2006.

[18] A. Khaliq, "Exergy analysis of gas turbine tri- generation system for combined production of power heat and refrigeration," Int. J. Refrig., vol. 32, pp. 534-545, 2009.

[19] M. Jonsson and J. Yan, "Ammonia-water bottoming cycles: a comparison between gas engine and gas diesel engines as prime movers," Energy, vol. 26, no. 1, pp. 31-44. 2001.

[20] M. Dixit, A. Arora, S. C. Kaushik, "Energy And Exergy Analysis Of A Waste Heat Driven Cycle For Triple Effect Refrigeration," JTEN, vol. 104, 2015.

[21] C. A. Infante Ferreira, "Thermodynamic and physical property data equations for ammonia-lithium nitrate and ammonia-sodium thiocyanate solutions," Sol Energy, vol. 32, pp. 231-236, 1984.

[22] D. W. Sun, "Comparison of the performances of NH3-H2O, NH3-LiNO3 and NH3-NaSCN absorption refrigeration systems," Energy conversion management, vol. 39, pp. 357-368, 1998. 
[23] L. H. Zhu, S. J. Wang and J. J. Gu, "Performance investigation of a thermal-driven refrigeration system," International Journal of Energy Research, vol. 32, pp. 939-949, 2008.

[24] Z. Linghui and G. Junjie, "Second law-based thermodynamic analysis of ammonia/sodium thiocyanate absorption system," Renewable Energy, vol. 35, pp. 1940-1946, 2010.

[25] D. K. Anand and B. Kumar, "Absorption machine irreversibility using new entropy calculations," Sol Energy, vol. 39, pp. 243-56, 1987. 